\title{
Electromagnetic Waves Collected by a Dental Amalgam Filling Induced Balance Dysregulation and Dizziness over a Period Exceeding 10 Years
}

\author{
Yoshiro Fujii \\ Shin Kobe Dental Clinic, Kobe, Japan \\ Email: shin-kobe-dentalclinic@s9.dion.ne.jp \\ Received 5 September 2015; accepted 25 October 2015; published 29 October 2015 \\ Copyright (C) 2015 by author and Scientific Research Publishing Inc. \\ This work is licensed under the Creative Commons Attribution International License (CC BY). \\ http://creativecommons.org/licenses/by/4.0/

(c) (i) Open Access

\begin{abstract}
This case report describes a woman aged approximately 50 years who has suffered from balance dysregulation and dizziness for more than 10 years. Although the subject underwent several examinations to confirm the etiology of her symptoms, the root cause remained unknown. The symptoms were thought to be caused by electromagnetic wave hypersensitivity because the subject experienced uneasiness and dizziness when a cell phone was held close to her body. A cell phone was used to diagnose the collection of harmful electromagnetic waves, and an amalgam filling was determined to be the cause. The amalgam filling was removed under strict protection, and the subject's symptoms completely disappeared soon after the filling was removed.
\end{abstract}

\section{Keywords}

Electromagnetic Hypersensitivity, Amalgam Filling, Balance Dysregulation, Dizziness, Electromagnetic Waves

\section{Introduction}

With the development of information technology (IT) society, the use of electronic devices, such as cell phones and personal computers, has become increasingly widespread, thereby enabling communication on a global scale [1] [2]. Although these devices have facilitated communication, several reports have described abnormalities in the body caused by the electromagnetic waves emitted by the above mentioned electronic devices [3]-[10]. Physically unpleasant symptoms, such as headache, fatigue, tinnitus, dizziness, memory loss, irregular heartbeat, 
and whole-body skin lesions, caused by exposure to electromagnetic waves are recognized as electromagnetic hypersensitivity (EHS) [11]-[15].

In the field of dentistry, titanium dental implants have been commonly associated with antenna-like activity [16] [17], although the underlying mechanism remains unknown. In a previous report, the author of the present study described the development of scoliosis in response to exposure to electromagnetic waves [16]. The author also described the treatment of a subject's involuntary electromagnetic wave-induced movements using a gold alloy dental inlay [18] as well as dental treatments for dizziness and joint mobility disorders caused by harmful electromagnetic waves [19]. The present case report describes how the removal of a dental amalgam resolves a subject’s balance dysregulation and dizziness caused by electromagnetic waves.

\section{Case Report}

\section{Treatment and Results}

The present subject was a woman approximately aged 50 years who suffered from balance dysregulation and dizziness for more than 10 years. The subject underwent several examinations to confirm the etiology of her symptoms but the root cause remained unknown. Her symptoms sometimes had been diagnosed as a mental disorder, so she had been prescribed psychotropic drugs, but to no effect. She could not walk stably and was unable to climb even a single step without support (Figure 1).

The author diagnosed the subject's symptoms might be electromagnetic hypersensitivity, because the subject's symptoms were similar to other patients with electromagnetic hypersensitivity. When a cell phone was held at a distance of approximately $80 \mathrm{~cm}$ away from her chest, she felt uneasy and dizzy. This reaction was not induced by any psychological influences or a hypnosis effect because it continued to remain when the subject closed her eyes (Figure 2), suggesting hypersensitivity to electromagnetic waves [17]. Additionally, the subject exhibited some improvement in her level of balance dysregulation when the lower half of her face was covered with aluminum foil to shield her mouth from the harmful electromagnetic waves (Figure 3); her sensations of uneasiness and dizziness were similarly diminished even when the cell phone was held close to her body.

These findings suggested the presence of a material in her oral area that attracted harmful electromagnetic waves.

Thus, the Bi-digital O-ring test [20] [21] was used to identify this foreign material. First, an active cell phone was placed near the subject. Second, the author's assistant touched the suspicious dental material in the subject's mouth with a conductive probe while making an O-ring with the thumb and another finger. Third, the author tested the strength of the assistant's O-ring by pulling the assistant's fingers to split apart the O-ring. If the assistant's grip strength was deemed to be weaker than usual, the material currently in contact with the probe was classified as a likely conductor of harmful electromagnetic waves (Figure 4).

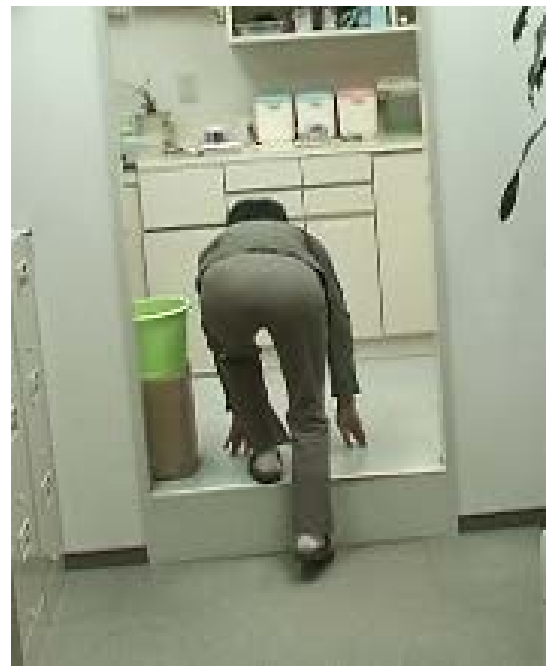

Figure 1. Image of the subject being unable to climb a single step without support. 


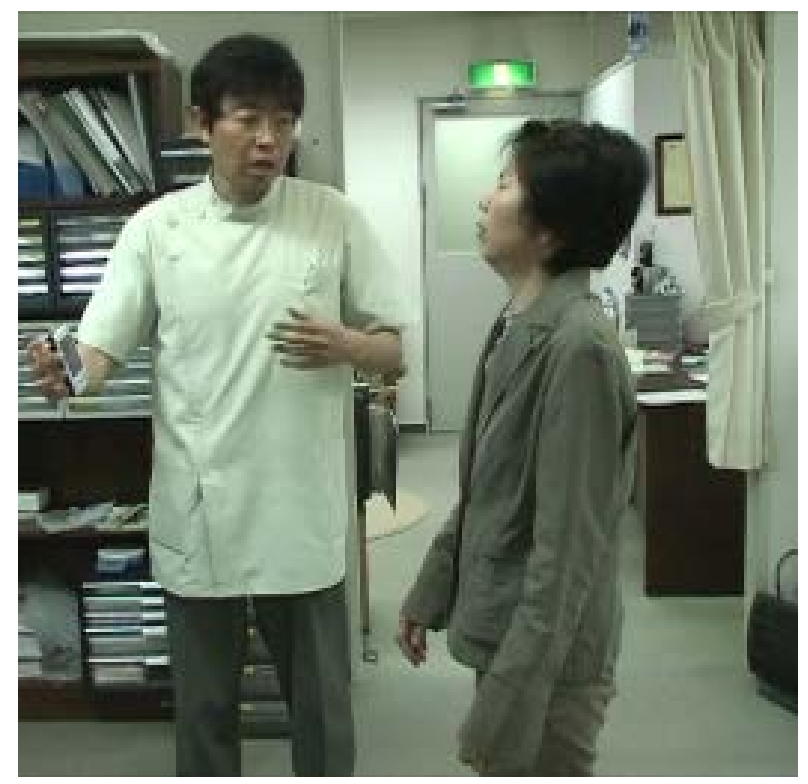

Figure 2. Image of the subject experiencing uneasiness and dizziness when a cell phone was held near her chest (distance: approximately $80 \mathrm{~cm}$ ). This sensation remained when the subject closed her eyes.

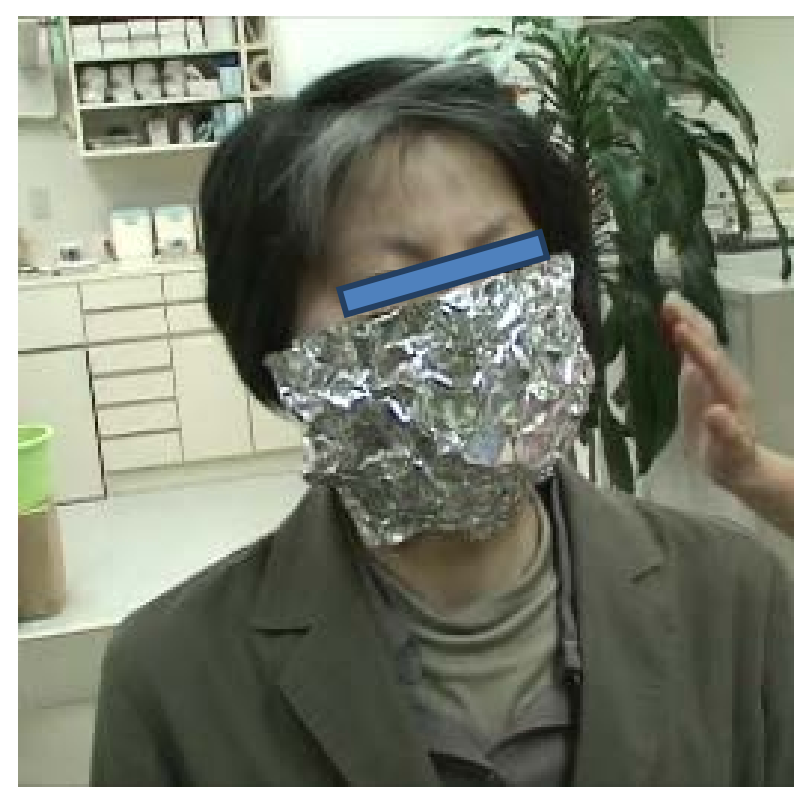

Figure 3. The lower half of the subject's face covered with aluminum foil to shield her mouth from the harmful electromagnetic waves.

This experiment identified an amalgam filling in the upper right second molar as the material most likely to collect harmful electromagnetic waves (Figure 5). Therefore, it was suspected that electromagnetic waves which the amalgam filling collected were causing her symptoms.

Accordingly, this amalgam was removed under strict protection (rubber dam, goggles, and an outside suction) to prevent the subject from swallowing any of the amalgam debris or from inhaling any mercury vapor during removal (Figure 6). Subsequently, within a short period of the amalgam removal, the subject no longer experienced uneasiness even when a cell phone was held close to her body. Moreover, she regained the ability to 


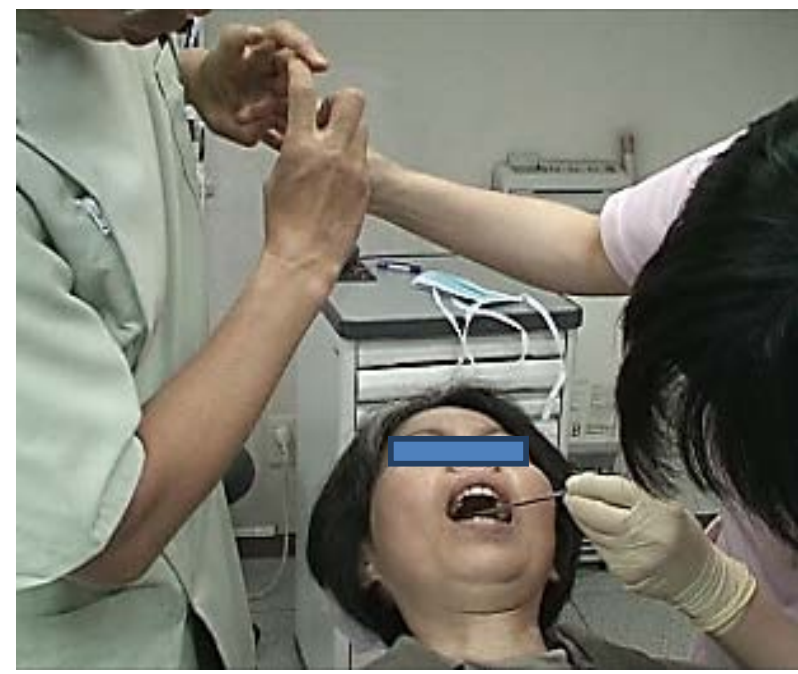

Figure 4. The author (in blue) is shown while testing the Oring strength of his assistant (in pink) when the assistant touches the suspected material in the subject's mouth with a conductive probe. Note: an active cell phone was placed near the subject's body (not visible in this figure).

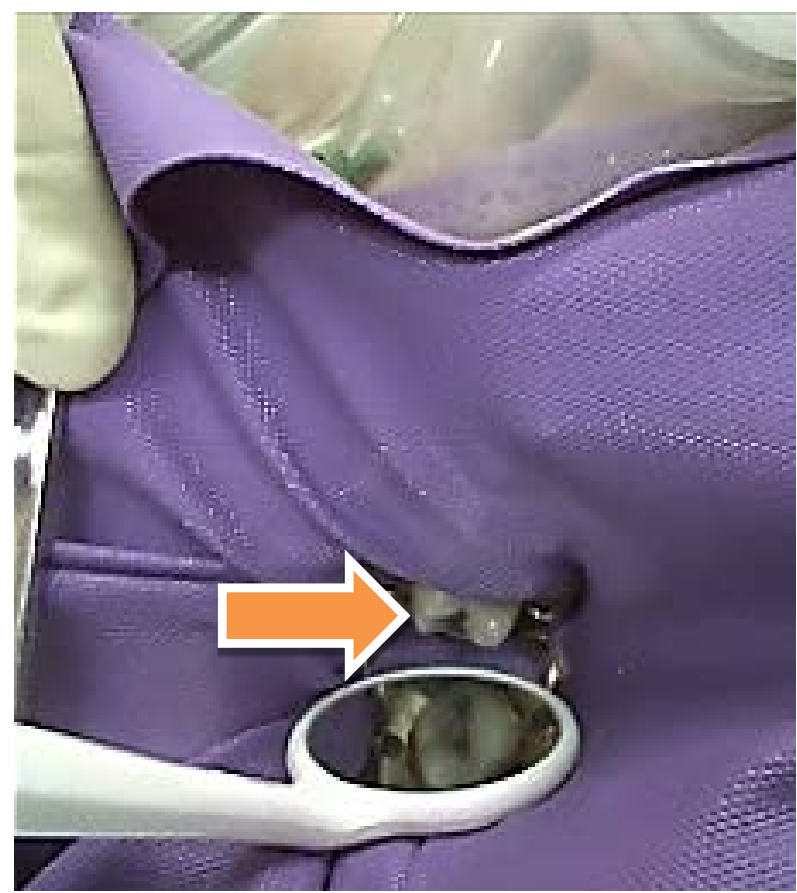

Figure 5. The Bi-digital O-ring test result indicated that an amalgam filling in the upper right second molar (arrow) is the most likely material to collect harmful electromagnetic waves.

walk stably and to climb easily without support (Figure 7).

The amalgam filling was replaced with a glass ionomer cement that was considered to be safer. The subject's post-procedural prognosis was good. This result was lasting; furthermore, neither did symptoms re-occur nor were there any side effect.

The actual experiment conducted in this case can be observed in the YouTube video

"Suffering from unsteadiness and dizziness for more than 10 years" 


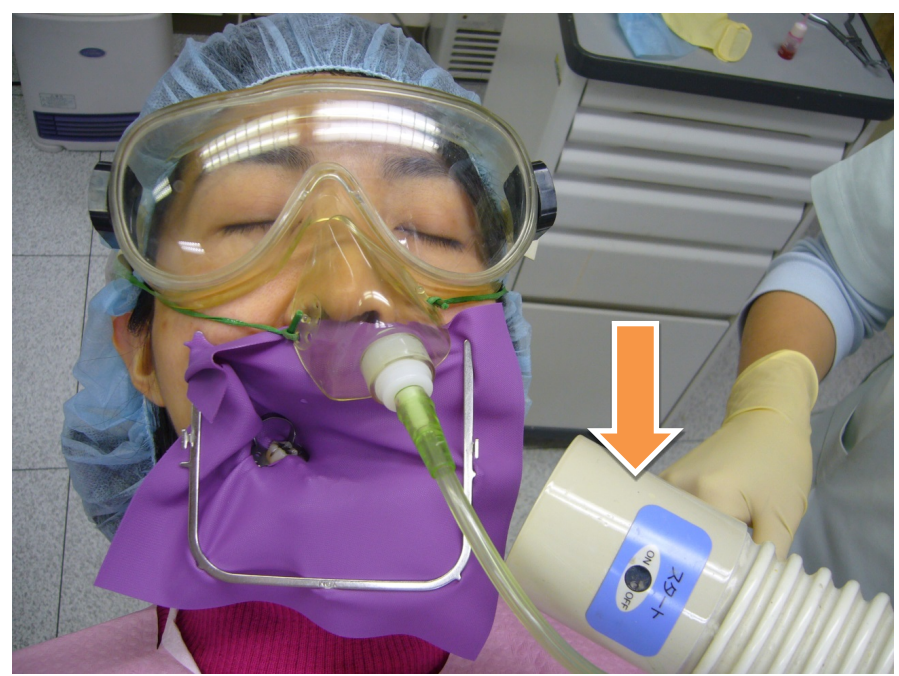

Figure 6. Image showing the amalgam removal under strict protection using a rubber dam, goggles, and an outside suction (arrow) so that the subject would not swallow any of the amalgam debris or inhale any mercury vapor during the amalgam removal (the subject is not shown in this sample image).

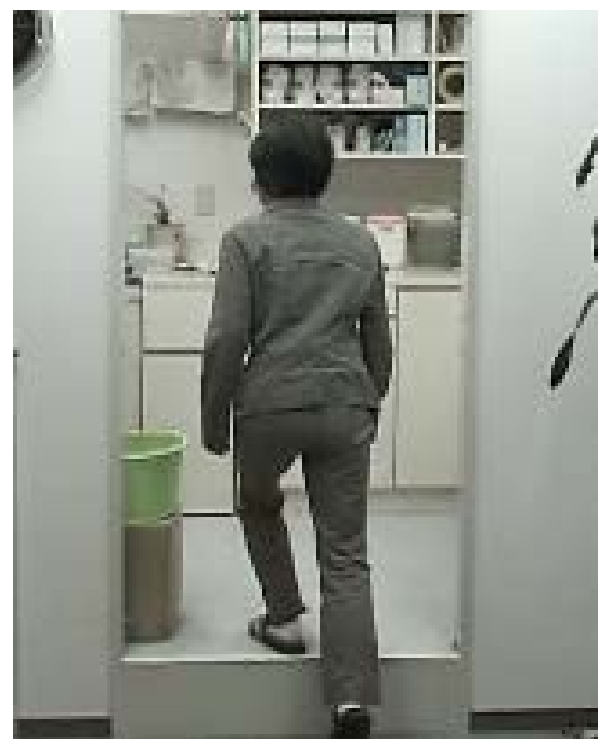

Figure 7. Image of the subject climbing a step easily without support soon after amalgam removal.

https://www.youtube.com/watch?v=Vnms7TnL5Og (last accessed 14/Oct/2015).

\section{Discussion}

Concerning the relationship between brain tumors and radio waves emitted by cell phones, the Interphone Study Group concluded that although cell phone use was not associated with an increase in the risk of glioma or meningioma, a trend toward an increased risk of glioma was observed at the highest usage levels. However, biases and error have prevented a causal interpretation of these data; the possible effects of long-term heavy cell phone usage require further investigation [22]. Other published reports do not support an association between the use of cell phones and the development of tumors of the brain or salivary gland, leukemia, or other cancers [23]-[25]; however, the described research did not sufficiently evaluate the risks among long-term heavy cell phone users 
over potentially long induction periods [23]. Accordingly, further studies are needed to account for longer induction periods, particularly with respect to slow-growing tumors with neuronal features [24].

The present author has published several reports concerning the relationship between dentistry and electromagnetic waves [16]-[19] [26] [27]. However, many articles only emphasize on the convenience of these electronic devices without addressing the potentially negative influences of the emitted electromagnetic waves on the body [28]. Metal components within the body can act as antennas that attract harmful radio waves and induce the aforementioned symptoms. In the field of dentistry, titanium dental implants are likely to be the material that is most commonly associated with antenna activity [16] [17]. The results of the present case study indicate that dental amalgams might also attract harmful electromagnetic waves. As described above, this collection of unpleasant symptoms is known as EHS [11]-[15], and although the underlying mechanism remains unknown, reduced blood flow within the brain is assumed to be involved [4].

The present author's research has found that removing metals that collect harmful electromagnetic waves and maintaining a sufficient distance from electronic devices, such as cell phones, can reduce some of the harmful effects of electromagnetic waves and may permit short periods of lower risk and beneficial cell phone usage. However, the removal of dental materials was not previously found to decrease the influences of harmful electromagnetic waves [29], and the effects of electromagnetic waves on the body remain unclear. As the author previously suggested, titanium implants collect harmful electromagnetic radiation more easily than pure gold metal [16]. The underlying collection mechanism has been partially elucidated by the Bi-digital O-ring test [30] [31]. As this test indicated that the radio waves exerted deleterious effects on the body, the test might be a useful diagnostic tool for conditions associated with harmful electromagnetic waves.

According to a report by Hagström et al., personal computers and mobile phones are the most commonly perceived EHS-triggering sources. Additionally, the best way to reduce EHS symptoms is to avoid the causative electromagnetic fields [29]. The removal of the dental material with the aim to reduce the collection of harmful electromagnetic radiation is not a widespread practice. However, the procedure introduced in this report might represent an effective approach for treating EHS.

In the current case study, balance dysregulation and dizziness occurred when the subject had an amalgam dental filling that appeared to act as an antenna and collect harmful electromagnetic waves. The treatment involved the removal of only the subject's amalgam filling and replacement with a glass ionomer cement filling that did not appear to attract harmful electromagnetic waves and effectively eliminated the subject's balance dysregulation and dizziness, which might have been caused by EHS. However, further studies are required to confirm the abovementioned hypothesis.

In the field of dentistry, amalgam fillings containing approximately $50 \%$ mercury have been used for almost 200 years, and their use has been controversial over this period. Such dental amalgams have been linked to many diseases; for example, dermatitis caused by allergic reactions to the mercury in these amalgams is a well-known condition in the medical community [32]-[34]. Furthermore, the author previously reported a case of non-allergic intractable dermatitis caused by mercury in a dental amalgam [35]. Recent evidence suggesting that small amounts of mercury are continuously released from amalgam fillings has fueled the controversy surrounding their use [36]. Since individuals who have received amalgam restorations exhibit higher mercury concentrations in their blood and urine than those who have not received amalgam restorations, mercury is thought to be released from the amalgam and distributed throughout the body [37] [38]. In the present case, all precautions were taken to avoid further exposure of the subject to mercury during amalgam filling removal. A rubber dam [39] [40] and an outside suction were used to prevent the subject from swallowing any of the amalgam debris or inhaling any mercury vapor [41].

\section{Conclusion}

Many reports have described individuals who suffer from EHS. The avoidance of harmful electromagnetic waves has been shown to reduce these symptoms and simultaneously improve patients' physical abilities. Dental materials may act as antennas and collect harmful electromagnetic waves. Therefore, dental procedures should be performed with extra caution in the right of this feature. The present report suggests that a dental amalgam attracts harmful electromagnetic waves. Removal of these amalgam fillings under strict protective conditions might be an effective method for avoiding the harmful influences of electromagnetic waves and for treating patients suffering from EHS. 


\section{Additional Information}

The informed consent for publication was obtained from the subject.

\section{References}

[1] Geser, H. (2004) Towards a Sociological Theory of the Mobile Phone. Release 3.0, University of Zurich, Zurich. http://socio.ch/mobile/t_geser1.htm/

[2] van Dijk, J. and Hacker, K.(2003) The Digital Divide as a Complex and Dynamic Phenomenon. The Information Society, 19, 315-326. http://dx.doi.org/10.1080/01972240309487

[3] (2014) http://www.holistic-dentistry.net/blog/2013/07/entry_242/

[4] Aalto, S., Haarala, C., Brück, A., Sipilä, H., Hämäläinen, H. and Rinne, J.O. (2006) Mobile Phone Affects Cerebral Blood Flow in Humans. Journal of Cerebral Blood Flow and Metabolism, 26, 885-900. http://dx.doi.org/10.1038/sj.jcbfm.9600279

[5] Feychting, M., Jonsson, F., Pedersen, N.L. and Ahlbom, A. (2003) Occupational Magnetic Field Exposure and Neurodegenerative Disease. Epidemiology, 14, 413-419. http://dx.doi.org/10.1097/01.EDE.0000071409.23291.7b

[6] Håkansson, N., Gustavsson, P., Johansen, C. and Floderus, B. (2003) Neurodegenerative Diseases in Welders and Other Workers Exposed to High Levels of Magnetic Fields. Epidemiology, 14, 420-426. http://dx.doi.org/10.1097/01.EDE.0000078446.76859.c9

[7] Ahlbom, A. (2001) Neurodegenerative Diseases, Suicide and Depressive Symptoms in Relation to EMF. Bioelectromagnetics Supplement, 5, 132-143. http://dx.doi.org/10.1002/1521-186X(2001)22:5+<::AID-BEM1029>3.0.CO;2-V

[8] Linet, M.S., Hatch, E.E., Kleinerman, R.A., Robison, L.L., Kaune, W.T., Friedman, D.R., Severson, R.K., Haines, C.M., Hartsock, C.T., Niwa, S., Wacholder, S. and Tarone, R.E.(1997) Residential Exposure to Magnetic Fields and Acute Lymphoblastic Leukemia in Children. The New England Journal of Medicine, 337, 1-7. http://dx.doi.org/10.1056/NEJM199707033370101

[9] Röösli, M., Moser, M., Baldinini, Y., Meier, M. and Braun-Fahrländer, C. (2007) Symptoms of Ill Health Ascribed to Electromagnetic Field Exposure-A Questionnaire Survey. International Journal of Hygiene and Environmental Health, 207, 141-150. http://dx.doi.org/10.1078/1438-4639-00269

[10] Edelstyn, N. and Oldershaw, A. (2002) The Acute Effects of Exposure to the Electromagnetic Field Emitted by Mobile Phones on Human Attention. Neuroreport, 13, 119-121. http://dx.doi.org/10.1097/00001756-200201210-00028

[11] Rea, W., Pan, Y., Yenyves, E., Sujisawa, I., Suyama, H., Samadi, N. and Ross, G. (1991) Electromagnetic Field Sensitivity. Journal of Bioelectricity, 10, 241-256. http://dx.doi.org/10.3109/15368379109031410 http://firstdonoharmblog.blogspot.jp/2011/05/electromagnetic-field-sensitivity.html

[12] Rubin, G.J., Das Munshi, J. and Wessely, S. (2005) Electromagnetic Hypersensitivity: A Systematic Review of Provocation Studies. Psychosomatic Medicine, 67, 224-232. http://dx.doi.org/10.1097/01.psy.0000155664.13300.64

[13] Rubin, G.J., Das Munshi, J. and Wessely, S. (2006) A Systematic Review of Treatments for Electromagnetic Hypersensitivity. Psychosomatic Medicine, 75, 12-18.

[14] Norbert, L. (2009) Electromagnetic Hypersensitivity. Advances in Electromagnetic Fields in Living Systems, 5, 167197. http://dx.doi.org/10.1007/978-0-387-92736-7_5

[15] Kimata, H. (2005) Microwave Radiation from Cellular Phones Increases Allergen-Specific IgE Production. Allergy, 60, 838-839. http://dx.doi.org/10.1111/j.1398-9995.2005.00802.x

[16] Fujii, Y. (2012) Do Dental Implants Cause Scoliosis? A Case Report. Personalized Medicine Universe, 1, 79-80. http://dx.doi.org/10.1016/j.pmu.2012.05.012

[17] Fujii, Y. (2014) Sensation of Balance Dysregulation Caused/Aggravated by a Collection of Electromagnetic Waves in a Dental Implant. Open Journal of Antennas and Propagation, 2, 29-35. http://dx.doi.org/10.4236/ojapr.2014.23004

[18] Fujii, Y. (2014) Gold Alloy Dental Inlay for Preventing Involuntary Body Movements Caused by Electromagnetic Waves Emitted by a Cell Phone. Open Journal of Antennas and Propagation, 2, 37-43. http://dx.doi.org/10.4236/ojapr.2014.24005

[19] Fujii, Y. (2015) Dental Treatment for Dizziness and Joint Mobility Disorder Caused by Harmful Electromagnetic Waves. Open Journal of Antennas and Propagation, 3, 1-7. http://dx.doi.org/10.4236/ojapr.2015.31001

[20] Omura, Y. (1990) Bi-Digital O-Ring Test for Imaging and Diagnosis of Internal Organs of a Patient. Patent No. 5188107.

[21] http://bdort.org/

[22] Interphone Study Group (2010) Brain Tumor Risk in Relation to Mobile Telephone Use: Results of the Interphone In- 
ternational Case-Control Study. International Journal of Epidemiology, 39, 675-694. http://dx.doi.org/10.1093/ije/dyq079

[23] Johansen, C., Boice Jr., J.D., McLaughlin, J.K. and Olsen, J.H. (2001) Cellular Telephones and Cancer-A Nationwide Cohort Study in Denmark. Journal of the National Cancer Institute, 93, 203-207. http://dx.doi.org/10.1093/jnci/93.3.203

[24] Inskip, P.D., Tarone, R.E., Hatch, E.E., Wilcosky, T.C., Shapiro, W.R., Selker, R.G., Fine, H.A., Black, P.M., Loeffler, J.S. and Linet, M.S. (2001) Cellular-Telephone Use and Brain Tumors. The New England Journal of Medicine, 344, 79-86. http://dx.doi.org/10.1056/NEJM200101113440201

[25] Muscat, J.E., Malkin, M.G., Thompson, S., Shore, R.E., Stellman, S.D., McRee, D., Neugut, A.I. and Wynder, E.L. (2000) Handheld Cellular Telephone Use and Risk of Brain Cancer. Journal of the American Medical Association, 284, 3001-3007. http://dx.doi.org/10.1001/jama.284.23.3001

[26] Fujii, Y. (2007) The Dental Treatment That Used Environment of Electromagnetic Wave. Acupuncture and ElectroTherapeutics Research, 32, 291.

[27] Fujii, Y. (2009) The Consideration of the Electromagnetic Wave in Dental Material Substitution. Acupuncture and Electro-Therapeutics Research, 34, 89.

[28] http://www.healthit.gov/providers-professionals/benefits-electronic-health-records-ehrs

[29] Hagström, M., Auranen, J. and Ekman, R. (2013) Electromagnetic Hypersensitive Finns: Symptoms, Perceived Sources and Treatments, a Questionnaire Study. Pathophysiology, 20, 117-122. http://dx.doi.org/10.1016/j.pathophys.2013.02.001

[30] Omura, Y. and Losco, M. (1993) Electro-Magnetic Fields in the Home Environment (Color TV, Computer Monitor, Microwave Oven, Cellar Phone, etc.) as Potential Contributing Factors for the Induction of Oncogen C-Fos Ab1, Oncogen C-fos Ab2, Integrin Alpha 5 Beta 1 and Development of Cancer, as Well as Effects of Microwave on Amino Acid Composition of Food and Living Human Brain. Acupuncture and Electro-Therapeutics Research, 18, 33-73.

[31] Omura, Y., Losco, M., Omura, A.K., Yamamoto, S., Ishikawa, H., Takeshige, C., Shimotsuura, Y. and Muteki, T. (1991) Chronic or Intractable Medical Problems Associated with Prolonged Exposure to Unsuspected Harmful Environmental Electric, Magnetic, or Electro-Magnetic Fields Radiating in the Bedroom or Workplace and Their Exacerbation by Intake of Harmful Light and Heavy Metals from Common Sources. Acupuncture and Electro-Therapeutics Research, 16, 143-177.

[32] Adach, A., Horikawa, T., Takahashi, T. and Ichihashi, M. (2000) Mercury-Induced Nummular Dermatitis. Journal of the American Academy of Dermatology, 43, 383-385. http://dx.doi.org/10.1067/mjd.2000.102457

[33] Feuerman, E.J. (1975) Recurrent Contact Dermatitis Caused by Mercury in Amalgam Dental Fillings. International Journal of Dermatology, 14, 657-660. http://dx.doi.org/10.1111/j.1365-4362.1975.tb00158.x

[34] Thomson, J. and Russell, J.A. (1970) Dermatitis Due to Mercury Following Amalgam Dental Restorations. British Journal of Dermatology, 82, 292-297. http://dx.doi.org/10.1111/j.1365-2133.1970.tb12440.x

[35] Fujii, Y. (2015) A Case of Non-Allergenic Intractable Dermatitis Which Was Likely Caused by the Mercury Contained in Dental Amalgam. The Journal of Dentist, 2, 63-66. http://dx.doi.org/10.12974/2311-8695.2014.02.02.4

[36] Bates, M.N. (2006) Mercury Amalgam Dental Fillings: An Epidemiologic Assessment. International Journal of Hygiene and Environmental Health, 209, 309-316. http://dx.doi.org/10.1016/j.ijheh.2005.11.006

[37] Abaraham, J.E., Svare, C.W. and Frank, C.W. (1984) The Effect of Dental Amalgam Restorations on Blood Mercury Levels. Journal of Dental Research, 63, 71-73. http://dx.doi.org/10.1177/00220345840630011801

[38] Olstad, M.L., Holland, R.I., Wsndel, N. and Petteson, A.H. (1987) Correlation between Amalgam Restorations and Mercury Concentrations in Urine. Journal of Dental Research, 66, 1179-1182. http://dx.doi.org/10.1177/00220345870660061701

[39] Berglund, A. (1997) Mercury Levels in Plasma and Urine after Removal of Amalgam Restorations: The Effect of Using Rubber Dams. Dental Materials, 13, 297-304. http://dx.doi.org/10.1016/S0109-5641(97)80099-1

[40] Nimmo, A., Werley, M.S., Martin, J.S. and Tansy, M.F. (1990) Particulate Inhalation during the Removal of Amalgam Restorations. The Journal of Prosthetic Dentistry, 63, 228-233. http://dx.doi.org/10.1016/0022-3913(90)90110-X

[41] Safe Removal of Amalgam Fillings. http://iaomt.org/safe-removal-amalgam-fillings/ 